\title{
Post-truth and the Search for Objectivity: Political Polarization and the Remaking of Knowledge Production
}

\author{
Shreeharsh Kelkar \\ UNIVERSITY OF CALIFORNIA, BERKELEY
}

\begin{abstract}
The United States has entered an era of "post-truth" as even seemingly proven facts seem open to contestation. The contests over facts range from the existential (when conservatives deny climate change) to the trivial (when the Trump administration questions the audience figures of its own inauguration ceremony). This essay combines two literatures on post-truth that rarely speak to each other: institutional political science analyses of American political polarization and STS analyses of "objectivity" in science and public life. I argue that post-truth is the outcome of two interlocking processes that have transformed the American public sphere: (1) the re-configuring of American political identities around the Republican and Democratic parties, and (2) the establishment of an alternative media ecosystem around the Republican Party whose legitimacy derives from its questioning of the "objectivity" of mainstream media institutions. Drawing on STS theorizations of the construction of objectivity, I contend that to recreate an objective public sphere will require an institutional arrangement that is based not on demarcating facts from values-or right facts from wrong facts-but on demarcating people and institutions who seek to enter this public sphere.
\end{abstract}

\section{Keywords}

post-truth; political polarization; objectivity; science; technology; media; motivated reasoning

\section{Introduction}

In February 2017, in the wake of Donald Trump's shocking upset of Hillary Clinton in the 2016 US Presidential Election, the science writer Elizabeth Kolbert (2017) took to the pages of the New Yorker to describe "why facts don't change our minds." Kolbert was concerned with the phenomenon of "post-truth," a word that is used to characterize a range of emerging public debates around epistemology in the contemporary United States, such as when climate deniers question the research on global warming or vaccine skeptics challenge the power of vaccines. The Trump administration has taken matters to another level by disputing the photographs showing the size of the crowds at its inauguration, by alleging — without any evidence-that voter fraud is

'Shreeharsh Kelkar, Email: shreeharsh@gmail.com

Copyright (C) 2019 (Shreeharsh Kelkar). Licensed under the Creative Commons Attribution Non-commercial No Derivatives (by-nc-nd). Available at estsjournal.org. 
rampant, and by openly attacking established media institutions as purveyors of "fake news" (see Figure 1).

Drawing on research in philosophy and psychology, Kolbert argued that the cause of post-truth is that human reason was never designed to produce truth or explain phenomena in the first place; rather, it was an evolutionary adaptation to humans' "hypersociability," whose purpose was to help humans win arguments by making their tribe's explanation sound more plausible in the face of other-group opposition. It therefore doesn't surprise Kolbert that some people (on the other side, naturally) choose to question the legitimacy of the science of global warming or circulate obviously false conspiracy theories: their loyalty to their tribe comes before their reason.

Donald J. Trump

@realDonaldTrump

The FAKE NEWS media (failing @nytimes, @CNN, @NBCNews and many more) is not my enemy, it is the enemy of the American people. SICK!

3

The FAKE NEWS media (failing @nytimes, @NBCNews, @ABC, @CBS, @CNN) is not my enemy, it is the enemy of the American People! RETWEETS LIKES

Figure 1: President Trump's tweets declaring his war on the established media institutions; the original tweet is at the top and the modified tweet (with ABC and CBS added to the original "fake news" troika of the NYT, CNN and NBC) is at the bottom. Screenshots taken from (Drum 2017).

Kolbert's article is notable both for this framing and by what it does not include. Surprisingly, for an article written for a US audience, no mention is made of rising political polarization, the fractured media ecosystem, or the rise of curatorial platforms like Facebook. Instead, the piece is grounded mostly in simple laboratory experiments done by social 
psychologists and philosophers..$^{2}$ Even more surprising is its almost overt endorsement of an evolutionary psychology paradigm to explain the post-truth world, something I assume would not pass muster in the New Yorker if the topic was, say, gender norms." "Living in small bands of hunter-gatherers," says Kolbert, "our ancestors were primarily concerned with their social standing, and with making sure that they weren't the ones risking their lives on the hunt while others loafed around in the cave. There was little advantage in reasoning clearly, while much was to be gained from winning arguments." Of course, as with most explanations that draw on the habits of our ancestor "hunter-gatherers" to explain contemporary phenomena, this one cannot explain variation such as why climate denialism exists among US conservatives but not European ones.

Sophisticated STS analyses of the relationships between states, experts, and publics that do tend to be grounded in particular socio-historical realities are, of course, nowhere to be found in Kolbert's piece. But the politics of post-truth in the Trump age has made STS scholars deeply uneasy as well. Does STS, they wonder, have something to do with the emergence of post-truth, given that STS scholars have often been sympathetic to publics who distrust established centers of knowledge production?

This debate between STS scholars recently played out in the pages of the journal Social Studies of Science. In response to Fuller's (2016) claim that STSers should embrace the post-truth age because it is the "the inevitable outcome of greater epistemic democracy" that STS has been fighting for, Sismondo $(2017,3)$ argued that the crude techniques employed by the post-truth warriors of the right ("[a] Twitter account alone does not make what we have been calling knowledge") bear little resemblance to the knowledge-making techniques that classic works of STS have usually put under the microscope, which require painstaking social, political, technical, and institution-building work. In response, Harry Collins and collaborators argued that, far from being crude or easy, post-truth, too, "is hard work" (Collins, Evans, and Weinel 2017, 581). They contend that STSers need to position their field as more than just another political voice in the battle against post-truth. Rather, STS should be positioned as an objective science of expertise with the ability to inform the policy-making process about the right experts to trust for a given political problem.

Collins et al. (2017) are both right (post-truth is hard work) and wrong (the hard work means that it will be impossible to turn STS into a science of expertise). Post-truth is indeed hard work and has been extensively documented by political scientists studying American political polarization. Through the 1960s and 70s, American conservatives (correctly) realized that the two legitimate producers of knowledge, academia and the mainstream media, were populated primarily by liberals. In response, conservatives created a parallel information ecosystem of think tanks and media outlets, whose influence on the Republican Party has been steadily increasing.

2 Kolbert does not use, for instance, the much more sophisticated social-psychological experiments conducted by researchers like Brendan Nyhan and Dan Kahan, which we will consider later in this essay.

${ }^{3}$ For an anthropological criticism of an evolutionary psychology perspective on gender norms, see Helmreich and Paxson (2005). 
The Democratic Party, in contrast, continues to rely on the traditional knowledge producers; but in the circular logic of political polarization, that only de-legitimizes them further in the eyes of conservative audiences. This explanation, however, means that Collins et al.'s (2017) preferred next step of turning STS into a robust science of expertise relevant to the policy-making process is bound to fail, since STS is very much part of the mainstream knowledge-producing tradition rooted in academia, and as such, part of the very enterprise that the conservative information ecosystem is trying to de-legitimize.

In this essay, I attempt to put into conversation two literatures that rarely talk to each other: political science analyses of American political polarization and the resultant transformation of institutions, and STS analyses of objectivity in science and public life. American political scientists have painstakingly documented how the United States polity re-organized in response to the social movements of the 1960s (Sides and Hopkins 2015). As a result, the two major US political parties and their constituencies sorted themselves into competing and opposing positions on a number of vital issues: the size and role of the welfare state, the scope and status of abortion, and the parameters of religion in public life. This political polarization transformed the knowledge production eco-system, which now bifurcated into a mainstream (academia + traditional media institutions) and a new insulated conservative one, each with their own constituent publics (Grossman and Hopkins 2016b, 129-198). These transformations explain the politicization of the scientific consensus on issues like climate change as well as the decline in the trust that conservatives have in the mainstream institutions of science and expertise (Gauchat 2012).

And yet, when political scientists seek to explain the distrust that conservatives express in scientific and media institutions, they often fall back on a concept called "motivated reasoning" drawn from social psychology. "Motivated reasoning" is the idea that because human reasoning powers are directed towards particular ends, we tend to pick facts that best fit our needs and motivations. "Motivated reasoning" is thus the topic of Elizabeth Kolbert's New Yorker piece with which I opened this essay, although she does not use that term.) In this socialpsychological explanation, motivated reasoning is a human universal, perhaps a product of evolution: all human beings do it, including experts. It raises the profoundly disturbing possibility of a scientific end to our Enlightenment hopes that experts-let alone publics-can be rational, that they can neatly separate facts from values and facilitate a harmonious society.

While the research on motivated reasoning has produced some fascinating insights (Tucker et al. 2018), it falls into the same trap as social psychological research in general. First, the research black-boxes the production of scientific facts themselves, taking them as the unproblematic endpoints of a straightforward process of knowledge-making. Second, by positing its causal mechanism deep inside the human mind, it is unable to account for variations within expert-public disagreements, for instance, why particular scientific issues and institutions get politicized (e.g. why the American EPA is more politicized than the FDA), or why they get politicized differently in different national contexts (why climate change denial is prevalent among US conservatives but not among European ones). Third, in keeping with the strongly 
applied and techno-solutionist bent of social psychology, motivated reasoning researchers' "solution" to this crisis often takes the form of standard psychological interventions, e.g. implicit bias training or self-affirmation interventions, which are hard to translate from the laboratory into the world (see Konnikova 2014).

It is the contention of this paper that sophisticated STS analyses of objectivity when combined with the institutionalist political science literature on polarization can both explain the phenomenon of post-truth better than the invocations of motivated reasoning as well as help think about the future. STS researchers have argued that the objectivity of technical apparatuses, social institutions, and facts is constituted together. By shifting the focus from facts to institutions and apparatuses, this research suggests that the road ahead lies less in thinking about the cognitive mechanisms through which humans deem facts to be true or false, but in re-configuring media institutions and the public sphere such that they both represent a broad range of interests and positions found in the polarized polity and curtail those who argue in bad faith.

To elaborate this argument in detail, the following sections of this paper take up, in turn: (1) how the intersection of political polarization and the history of media technologies combined to create a polarized information ecosystem that undermined much of the American public's trust in the institutions of knowledge production (i.e. the mainstream media and universities); (2) why STS theories of objectivity can better explain the polarized information ecosystem than motivated reasoning; (3) what all of this means for what comes next in navigating the treacherous environment of the post-truth age, both for STS in particular, and the mainstream knowledge production institutions in general.

\section{Political Polarization, Technological Change, and the Transformation of Knowledge Production}

In this section, I explain the trust crisis of American media institutions in terms of three main factors: the rise of political polarization, the growth of the internet and the birth of new kinds of journalistic voices, and finally, the explosive growth of media distribution platforms like Facebook and Google. I describe how conservative activists created new (right-wing) media institutions, with an alternative point of view, to compete with the mainstream media institutions. Technological changes-the rise of the internet and distribution platforms like Facebook-accelerated this transformation by better connecting these new institutions to their audiences.

As historians of American media have shown, American newspapers reached their current ideal of objectivity only in the 20 ${ }^{\text {in }}$ century (Schudson 1981; Starr 2005). In the early 19 century, American newspapers were supposed to be partisan; the newspaper was nothing more than the mouthpiece of a particular political group. It was in the middle of the $19^{\text {in }}$ century that the idea of something called the "news" took hold: this shift went hand-in-hand with the rapid industrialization of the United States, the growth of mass advertising, and the creation of a new middle class. Even then, however, journalists did not see their job as bringing "facts" to their 
audience's attention. Instead, they viewed their job being as much about entertainment as enlightenment, as much about persuasion as reportage.

Three developments in the late $19^{\text {th }}$ and early $20^{\text {th }}$ centuries precipitated the next round of changes. The development of the telegraph led to the creation of wire services that produced "facts," because they had to cater to consumers of different political beliefs. The New York Times pioneered an "information" model of journalism to appeal to its upper-middle class, relatively elite, audience. And finally, the experience of propaganda in World War I taught journalists that facts had to be carefully examined since, far from being a natural attribute of the world, they could be constructed by governments and other organizations for nefarious purposes (Schudson 1981).

It is thus in the 1930s that the ideal of "objectivity" in journalism-the way we understand it today-took hold. To become objective, newspapers and reporters instituted a whole host of procedures and norms. Organizationally, they separated their business and editorial divisions so that the business of news (revenue and advertising) should not interfere with the making of news. On the printed page, they began to keep facts, opinions and advertisements separate by clearly delineating them. And they started to report (political) conflicts by giving equal coverage to every side while the reporter stayed invisible. These changes were buttressed by two other shifts in the post-World War II period. Journalism sought to become a profession, as reflected in the rise of journalism schools and journalism degrees. As the US national security state grew and scandals like Watergate exploded, journalists started to see themselves as watchdogs who uncovered the underhanded dealings of corporations and the state. The style of objectivity that emerged out of these changes is today embodied by some of the most well-known American media institutions that span print, radio, and television: the New York Times, the Washington Post, Time Magazine, Newsweek, the Atlantic Monthly, CBS, NBC, CNN, NPR, and others (Schudson 1981).

The rise of journalistic objectivity (1930-2000 approximately) was aided by a political environment that was relatively un-polarized. In the period from 1900-90, the constituents of both the major US political parties embodied a whole spectrum of views on some of the most salient ideological issues in public life (e.g. the role of the state in regulating private enterprise or the role of religion in public life). On each of these issues, both parties included people who supported opposite sides i.e. the parties were ideologically scrambled (Sides and Hopkins 2015). Ironically, this was only possible because both parties participated in the systematic disenfranchisement of African-Americans. Thus Franklin Roosevelt's transformative New Deal reforms passed only because of the support of Democratic politicians in the South; yet, the support of Southern politicians hinged on restricting African-Americans' access to the benefits of the New Deal (Katznelson 2005).

Prodded by the success of the Civil Rights Movement in contesting white supremacy in the South, the Democratic Party embraced civil rights in the 1960s. Consequently, Southern whites started to leave the party, beginning the end of an era where both parties had assembled ideologically-broad coalitions. Over the next three decades, the two major US political parties began catering to entirely different constituencies and sorted themselves neatly into two 
opposing ideological camps with hardly any overlap, a phenomenon that political scientists call "polarization." Thus, on a number of vital issues, like the size and role of the welfare state, the scope and status of abortion, the value of diversity and immigration, or the parameters of religion in public life, the two parties have diametrically opposite and neatly symmetric positions. This is because they appeal to very different groups. Republicans are the party of managers, evangelicals, and (many) non-college educated whites, while Democrats are the party of organized labor, professionals, and minorities (see Sides and Hopkins 2015 for a survey of the vast political science literature on American political polarization).

In an era where both political parties presided over coalitions that spanned the ideological spectrum, newspapers could practice a detached objectivity through which they could be critical of all political persuasions. Political polarization however raised serious questions about journalistic objectivity as practiced. As polarization increased, partisans on both sides, especially conservatives, started to accuse mainstream media institutions of exhibiting "journalistic bias." While journalists and academics studiously followed objective norms and cast themselves as experts, they were always more left-of-center in their own politics. Conservatives, not unreasonably, perceived this as "bias," and therefore sought to create their own information ecosystem of think tanks and media. Aided partly by regulatory changes, this led to the creation of an alternative right-wing media ecosystem (like cable news channels and conservative talk radio) and new audiences who consumed them. A key feature of this alternative ecosystem was its focus on the biases of mainstream media institutions.

The success of the alternative right-wing media ecosystem is reflected in its outsized influence on setting the goals of the Republican Party, a truly unprecedented state of affairs. Political scientists Matt Grossman and David Hopkins argue that "the establishment of an explicitly right-of-center media ecosystem as a conscious alternative to 'mainstream' journalism allows conservative media personalities to exert an influence over Republican officeholders and voters that has no true counterpart among Democrats" (Grossmann and Hopkins 2016a). This has led to an information asymmetry in terms of the news and knowledge that circulates amongst publics of different political persuasions. While the right relies on its alternative information system, the left relies on

\begin{abstract}
traditional news media and intellectual sources [e.g. university research] that often implicitly flatter the Democratic worldview but do not portray themselves or their consumers as engaged in an ideological conflict. Similarly, left-of-center think tanks have adapted to conservative upstarts by frequently opposing them in policy debates, but still retain broader ties to scholarly researchers and closer adherence to academic norms. (Grossmann and Hopkins 2016a)
\end{abstract}

The rise of the internet and the growth of internet publishing further complicated matters. The internet took classifieds away from newspapers and magazines, thereby taking away a chunk of their revenue; further, it brought forth a new class of proto-journalists: bloggers, citizen-activists, advocates, who utilized it to reach a broader audience. These new voices did not necessarily subscribe to the established model of journalistic objectivity, where the journalist 
remains invisible and reports all sides of a conflict. Instead, they created a new genre of writing (embodied today in outlets like Vox and Talking Points Memo) embodying a different style of objectivity: their writing style accords a prominent space to facts but proudly spurns the invisible-reporter view-from-nowhere model of the NYT or CNN. The writer's loyalties are clear, facts and opinions are mixed, and every side does not get equal (or similar) coverage (Farrell and Drezner 2007).

Berry and Sobieraj (2014) have characterized this emerging internet-driven media ecosystem as "the outrage industry." They argue, however, that the outrage industry is not just a product of political polarization and technological change; instead, its key cause is business models that favor generating outrage over substantive coverage. They also point out that the "outrage industry," while existing on both the left and the right, is fundamentally asymmetric; the right has far more media institutions and audiences that relish outrage; both engage far more in systematically flouting established norms of media objectivity. This is because much of the right-wing media ecosystem is built around criticizing mainstream media institutions by generating outrage; on the left, audiences are far more open to consuming mainstream media coverage.

Finally, perhaps nothing else has been more consequential for media institutions than the rise of curatorial "platforms": especially Facebook and Google, who function as distribution channels for both the mainstream (left-wing) and alternative (right-wing) media ecosystems, and who offer media institutions access to literally billions of potential consumers. These companies are loath to police the content that lands and circulates on their platforms; they argue that they have no politics, and are simply channeling the voice of information producers and consumers (Gillespie 2010). Unlike media institutions that maintained their objectivity through specific organizing practices like separating fact from opinion, platforms argue that they are objective because they use algorithms. In their telling, the relative absence of human judgment in the working of their algorithms, along with their ability to be perfectly reproducible, is the reason their curatorial decisions are objective, why they are mere conduits for the voice of their users (Gillespie 2014).

Google and Facebook position themselves as neutral platforms because they rely on advertising for revenue and because they want to be relevant to people of different political affiliations. They are also committed to the principle of what media scholars have called "context collapse" (Davis and Jurgenson 2014; Marwick and Boyd 2011). In their own words, Google wants to "organize the world's information and make it universally accessible and useful," while Facebook wants to give people "the power to build community and bring the world closer together" (from Losse 2019). These aspirations are sweeping in that they seek to dismantle the boundaries between activities such that everything (reading the news, watching TV, talking to friends, shopping) is mediated through these platforms. Platforms seek to blur the distinctions between the social and the commercial, the personal and the public, and the political and the non-political. To slightly twist a phrase coined by legal theorist Helen Nissenbaum (2009), platforms seek to muddy, even eliminate, the "contextual integrity" of particular activities so that 
they all start to be mediated by the technological machinery that platforms specialize in. Explicitly regulating content or content-producers is not conducive to the growth of platforms.

Established media institutions today thus face challenges on a variety of political and economic fronts. They must come up with new ways of earning revenue, new ways of engaging audiences, and new ways of gatekeeping to establish a reasonable public sphere that is crucial to democratic debate; most importantly, they must stop an influential audience, conservatives, from deserting this public sphere for an alternative (right-wing) one with its own set of alternative facts. They must both engage this alternative public sphere while not letting it set the terms of the coverage, all the while re-assuring their own partisans of their fundamental objectivity. Media theorist and STS scholar Mike Ananny (2018) argues that the question facing the networked press-by which he means "journalists, software engineers, algorithms, relational databases, social media platforms, and quantified audiences" ( $\mathrm{p} 4)$ - is the problem of imagining what "press freedom" means in an age of political polarization and new socio-technical infrastructures.

To sum up, political polarization and the rise of the internet have led to a polarized information ecosystem that consists of two, mostly non-overlapping, streams: a set of mainstream media institutions and a right-wing flank with its own set of alternative facts. Three factors have been crucial to this polarized information ecosystem: the work of conservative political activists in creating a parallel information ecosystem; the rise of-mostly conservative-audiences that look to these alternative media institutions as their main source of news; and finally, the rise of the platform-driven economy of attention that allows both media producers and consumers to find each other. Not surprisingly, mainstream media institutions face a crisis of objectivity and legitimacy.

\section{Explaining Post-truth: From "Motivated Reasoning" to the Architecture of Objectivity}

Many analysts have taken up a social-psychological concept called "motivated reasoning" to explain post-truth and several influential science journalists have now popularized it in their writings (e.g. Achenbach 2015; Beck 2017; Kolbert 2017; Konnikova 2014; Mooney 2011, 2012; Resnick 2017). In this section, I argue that "motivated reasoning" research has limited explanatory power in explaining post-truth and that its focus on "facts" and "truth" is too constricting when it comes to thinking about the future of the public sphere; in both of these, STS theories of objectivity may be more clarifying.

"Motivated reasoning" is an explanatory rubric to understand how people's pre-existing political beliefs shape their interpretation of the "facts." Political psychologists study motivated reasoning by presenting research subjects with certain facts, framed in particular ways, and asking them to make a decision based on their interpretation of the facts. They find that the most important factors shaping people's interpretation of facts are "partisanship," "prior issue opinions" and "identity threat" (Flynn et. al. 2017, 132-133). People, according to this theory, are often caught in a "tug-of-war between accuracy and directional motivations" (p134). The extent to which these motivations play a role in the acceptance of facts depends on the type of person (high-information, low-information) and the type of situation (politicized, non-politicized) in 
which the fact is presented. Thus politicized issues, which activate partisanship and identity threat, will favor directional motivations, while non-politicized issues are more likely to lead to a search for accuracy. On the other hand, high-information individuals, irrespective of their political affiliation, are far more likely to engage in directional motivated reasoning than lowinformation individuals because they can draw on their knowledge to craft a counter-argument or a rationalization (Flynn et al. 2017; Tucker et al. 2018).

Motivated reasoning researchers are quite clear that the solution to post-truth is not more scientific or media literacy, since high-information voters are more likely to engage in motivated reasoning (see also boyd 2018). Other findings in the research, however, seem to point to potential solutions: e.g. researchers find that "people who argue against their personal and political interests" are more likely to help squelch false rumors than an intervention from someone who is perceived to be on the other side (Tucker et al. 2018, 42-43). They also draw on a technique that social psychologists have developed in their work on stereotypes and discrimination, e.g. asking study participants to write self-affirming essays works to reduce identity threat and thereby the tendency towards motivated reasoning (see Steele 2011). However, these techniques, while useful in an experiment, are hard to fit into everyday contexts of media use, a fact that researchers themselves admit (Konnikova 2014).

While motivated reasoning research has led to some impressive insights, it only begs the bigger question. If politicized contexts are more likely to lead to directionally motivated reasoning, why are some issues more politicized than others and some facts and institutions seen as less "objective" than others? What is the process through which an issue or a fact becomes politicized?

STS theories of objectivity have long been concerned with this question. STS scholars understand "objectivity" as a process through which the trustworthiness of technical apparatuses and social institutions is built together such that specific publics come to see particular knowledge claims as robust and rooted in nature itself. Experimental facts produced in 17th century England were undergirded by the social authority of gentlemen-scientists (Shapin 1995). The late $19^{\text {t }}$ and early $20^{\text {" }}$ centuries saw the emergence of "mechanical objectivity": a push to produce knowledge through processes that even a machine can replicate. This push arose as much from a doubting public and competing institutions as it did from different experts' mistrust of their own subjectivity (Daston and Galison 2010). Thus, the development of cost-benefit analysis as a technique to evaluate public infrastructure projects in the United States was an outcome of the tussle between various regulatory agencies (Army Corps of Engineers, Bureau of Reclamation, Department of Agriculture) and powerful interest groups (power companies, railroads). Weak experts, hemmed in from many sides by different political interests, produced numbers to burnish the trust that was placed in them (Porter 1996). But numbers by themselves are not enough to produce objective facts. When the political stakes of an issue rise, many different experts and interest groups can produce a variety of facts around an issue. This leads to

4 The single-most important insight of this research is that scientific and media literacy programs are not the answer to post-truth. 
an "excess of objectivity" (Sarewitz 2004) that in turn may intensify the conflict around an issue rather than resolve it. For example, "the relative merits and dangers of shale gas development define in broad terms a fight between environmentalists and industrialists, both backed by different kinds of science" (Frickel et al. 2015, 308).

The history of political polarization and media ecosystems in the previous section confirms the main insight of STS: facts are durable and legitimate only within an underlying architecture of objectivity. The emergence of journalistic objectivity, as practiced by the NYT or $\mathrm{CNN}$, is an outcome of journalists establishing their expertise through particular practices of writing and newsroom organization. These practices both constituted and maintained the publics who gave them legitimacy. When those publics transformed, and new forms of journalism arose that were created by conservative activists and new technological infrastructures, mainstream journalistic institutions faced a crisis of objectivity and legitimacy.

By interpreting some of the findings of political psychologists against the backdrop of political polarization and the production of objectivity, we can avoid some of the aporias of motivated reasoning research caused by taking for granted the binary oppositions between facts/values, truth/falsity, and experts/laypeople. To demonstrate, let me take up a key experiment that received substantial coverage in the media. In April 2015, in the Washington Post, science reporter Chris Mooney (2015), drawing on a new research paper from Dan Kahan (2015), argued that motivated reasoning studies show that experts should be trusted more than ordinary people. Kahan and his collaborators asked the subjects in their subject pool (judges, lawyers, lawyers-in-training and laypeople, statistically representative of Americans) to interpret whether a given law was applicable to a hypothetical incident. The goal was to understand how different groups apply the rules of statutory interpretation. First, subjects were informed about the law that bans littering in a wildlife preserve. Next, they were told that a group of workers had left litter behind, in this case, reusable water containers. However, there was a catch: some were told that these were left behind by immigration workers helping illegal immigrants cross the USMexico border safely, while others were told that the litter belonged to a construction crew building a border fence. All were polled to understand their political and ideological affiliations. Predictably, depending on their political beliefs, people came down on different sides of the issue: Republicans tended to be more forgiving of the construction workers but less so of the immigration workers, whose actions they disagreed with. Democrats displayed the opposite tendencies. What was different was that judges and trained lawyers tended to reach this conclusion less than lay-people and untrained law students. Mooney (with some warrant from Kahan) drew a radical conclusion from this experiment: while experts are biased, they are less biased than laypeople; therefore, experts should be trusted more often than not, because they are more objective and less likely to let motivated reasoning lead them astray from the "correct" decision.

While it is true that experts can certainly resist motivated reasoning to some extent, and should certainly be trusted more on technical matters, STS theories of objectivity predict that expert agreement will break down when an issue becomes too contested. Consider, for instance, the US Supreme Court, which rules fairly often on issues of statutory interpretation, like the issue 
being analyzed in the Kahan study. In 2015, the US Supreme Court handed down a decision in King vs. Burwell, a challenge to President Obama's health care law (the Affordable Care Act, or ACA) that hinged precisely on that question. When the case was making its way through the lower courts, most legal experts quoted in the mainstream media outlets were incredulous that the case had any legs at all. Yet it eventually did reach the Supreme Court as lower courts disagreed amongst themselves about the result. The Supreme Court ruled 6-3 in the Obama administration's favor, but by no means unanimously, and with some stinging asides from Justice Scalia about the stupidity of the majority.

Now the Supreme Court justices (as well as the lower-court judges who disagreed with each other) are certainly experts: elite, well-trained, and at the top of their respective games. And yet, they disagreed strenuously about statutory interpretation when it came to a polarizing federal legislation. This does not mean, however, that judges are just politicians in robes (the thesis that Dan Kahan set out to debunk). The US Supreme Court actually resolves a great many cases with fairly clear majorities; more than a third of them through unanimous decisions (Corley et al. 2013). These cases hardly ever make it into the public eye, and they involve, to laypeople at least, what seem like arcane questions of regulation and jurisdiction (often questions of statutory interpretation). And yet, the Supreme Court is also hopelessly polarized on issues where the US polity is polarized and split: the Affordable Care Act, campaign finance funding, abortion, samesex marriage.

By shifting the question from how judges decide to how objective judicial decisions are produced through a dance between judges and the publics that they address, we avoid the contradictions of positing "natural" differences between facts and values, truth and falsity, and experts and laypeople. The Supreme Court justices are not exempt from the logic of political polarization; yet, they are able construct a great many decisions as objective based on the political salience of the issue in question. STS theories of objectivity, when combined with political science research on political polarization, offer more nuanced and context-sensitive interpretations of today's conflicts over "facts" in the United States than the concept of motivated reasoning. When experts and publics disagree over facts, its cause is best analyzed through examining the architecture of objectivity through which facts are produced, rather than trying to peer into the cognitive mechanisms through which particular people make particular decisions.

\section{Conclusion: The Road Ahead}

Given the analysis so far, how should mainstream knowledge producers (i.e. academics, mainstream journalists, and platforms) react to political polarization and their subsequent crisis of legitimacy? Can STS help us think about other models of objectivity that go beyond "facts" and "truth"? 


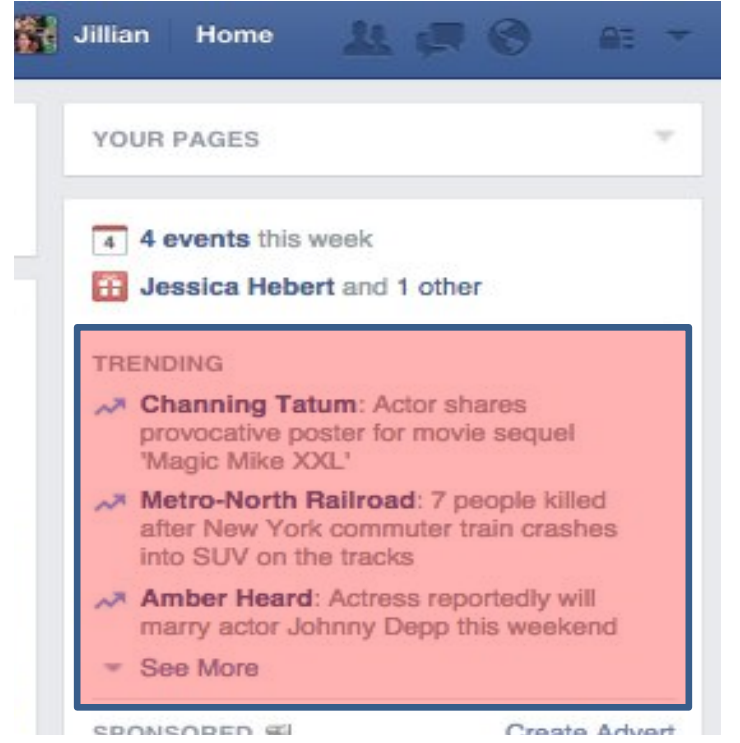

Figure 2: Back in 2016, Facebook prominently displayed what was "trending" on the top-right corner of its interface (highlighted in red in the adjacent figure). A report by the magazine Gizmodo claimed that the Trends feature was curated by a group of employees and that these employees were actively discriminating against conservative trending topics.

To look at two different models of objectivity in action, consider Facebook's widely divergent responses to the "trending" controversy and the furor over Russian misinformation efforts in the 2016 election. In 2016, the online publication Gizmodo revealed that Facebook's Trending Topics (a list of high-interest topics that Facebook used to display prominently on its site, see Figure 2) were not completely algorithmically derived but rather curated by a group of employees who made sense of what the algorithms found. If that were not enough, the report, channeling one of the conservative curators, alleged that the predominantly liberal group of curators, directed by their equally liberal Facebook bosses, was suppressing conservative news topics and thereby discriminating against conservatives (Nunez 2016). The two accusations struck at the heart of Facebook's carefully constructed architecture of mechanical objectivity: its emphasis on its pristine and human-independent "algorithms" and its contention that it was just a platform that reflected what its users did.

In response, Facebook fired its entire Trending staff and left the algorithms essentially unsupervised at the risk that the trends it reported would be incoherent. (It eventually retired the Trends feature altogether.) Facebook thus doubled down on its claims about the mechanical objectivity of its algorithms to resist being described in any way as "political." Facebook's management could have certainly dealt with the Trends controversy in a different way. They could have strengthened the job description of these Trends curators: treating it as a fundamental job that requires journalistic expertise rather than just as a stop-gap arrangement (see Gillespie 2016). They might have made the socio-technical process through which a Trend was captured and published more transparent, without divulging any trade secrets. They could even have 
hired more conservative curators and explicitly claimed that their curators were as representative as possible of the general US population. None of that happened; instead, Facebook stuck to its guns and defended its algorithms as mechanical, and therefore non-political and objective.

Facebook's approach to dealing with accusations that it aided Russian misinformation efforts-an affair with far higher stakes compared to the Trending controversy-has been notably different, perhaps because influential Facebook employees may have felt unease at their own complicity in the election of Donald Trump (Thompson and Vogelstein 2018). After some initial denials by Mark Zuckerberg, Facebook recently announced that independent fact-checkers would get privileged access to Facebook and would be able to flag egregious articles; these flags would be displayed as the articles circulated on the platform. In essence, Facebook created what is essentially a political solution to the fake news problem: it outsourced the verification of shared links to third parties who have established practices of adjudicating truth claims by media institutions.

In the pages of this journal, Noortje Marres (2018) has argued that an effort like Facebook's to solve its legitimacy problem by recourse to "facts" is a hurdle to genuine "knowledge democracy." The language of facts and fact-checking, especially when embedded in the opaque architectures of digital platforms, is a throwback, she says, to a "logical-empiricist conception of knowledge" and the "demarcation" it performs between something that is either true or false is dangerous because these facts are catered to very different audiences that often have little overlap. This corresponds to journalism scholar C. W. Anderson's (2018) claim that when journalists have doubled down on fact-making and "data," they may not necessarily have improved the practice of democracy.

In response, Steve Hoffman (2018) argues that Marres is misreading post-truth as a crisis of fact-making and that it is instead a consequence of "political demagoguery," "the culmination of an over three-decades long, very well-funded, and highly organized conservative campaign to foster an alternative fact-making universe constructed by conservative think tanks, lobbyists, media outlets, and professional science deniers whose goal has long been to create generalized distrust in mainstream institutions, free press journalism, professional scientists, and higher education" (448). Even if asserting the primacy of facts goes against the DNA of STS-thinking, Hoffman thinks, it is still necessary given the political moment.

Both Marres and Hoffman make valid points, but I would argue that a deeper consideration of American political polarization can help tease out a synthesis between them. Thus, while Marres is right to point out that the consumers of the true and false facts are very different constituencies, these two non-overlapping publics were in the making long before the architecture of social media was in place. Hoffman is also right that conservative activists actively went about creating an "alternative fact-making universe" to counter what they thought were the biases of mainstream knowledge-producing institutions. But this is not entirely a matter of "mystification and propaganda"; it is instead the product of a fundamental remaking of American political identities around two ideologically non-overlapping political parties.

Marres is right to be worried about the true/false demarcation that social media giants are putting into place through an alliance with journalistic fact-checkers. Yet, it is far from clear 
whether this will be a success or a failure, or even what success or failure might mean. After all, many issues remain unresolved: can the fact-checkers actually cope with the sheer volume of what gets shared on Facebook? How exactly will the judgment of the fact-checkers be incorporated into the black-box that is Facebook's Edge Rank algorithm, given the brute fact that items at the top of the Facebook newsfeed tend to be read the most? And most important, what if the fact-checkers themselves are deemed too liberal and therefore biased (the fate of established media institutions)? This last question is particularly salient. In his ethnographic study, Graves (2016) finds that professional fact-checkers are of both the old and new media worlds. They write in a vivid, link-heavy style that draws heavily from political blogs, their sense of mission derives deeply from what they see as the fracturing of media audiences, and they strive to engage multiple audiences (including more partisan fact-checkers and media watch-dogs) to seek legitimacy. And yet, they have very deep ties to elite journalistic institutions and a profound commitment to dominant ideals of journalistic objectivity. This leads to their fundamental limitation: while they can reflect on the facts of particular issues, their commitment to old-school journalistic objectivity leads them to avoid taking a stand on bigger political questions, and puts their legitimacy in a weird state of limbo. Their model of objectivity, rooted in their deeply-held belief that they "provide information, not political commentary" (Graves 2016, 212), runs up against the limits of political polarization.

So then, what lies ahead? I have argued so far that the causes of post-truth are multifaceted: the remaking of American political identities around the ideologically non-overlapping Democratic and Republican Parties, the creation of an alternative media ecosystem around the Republican Party, and the establishment of social media platforms that create new ways for media producers to connect to their constituent audiences. All of these together have thrown the objectivity of particular facts and institutions into doubt. Research in STS might conceivably help us think of other models of objectivity in our efforts to create trust-worthy media and knowledge producing institutions (i.e. trusted by the left and the right) in an age of polarization, information asymmetry, and curatorial platforms. In particular, STS research makes it clear that "facts" and "truth," construed in a particularly scientistic and black-boxed way, are not the only foundations of objectivity. The million-dollar question, of course, is to think of an alternative and create robust institutions that embody it.

One answer could lie in the demarcation of people and institutions rather than facts. In her comparison of the American, British and German regulation of biotechnology, Sheila Jasanoff $(2007,259)$ characterizes each national regulatory style as "contentious," "communitarian," and "consensus-seeking" respectively. In the German polity, for example, she finds an emphasis on the representativeness of knowledge-making bodies, while the United States hopes to resolve regulatory issues by having the different parties face off in an adversarial manner by having experts debate the "facts" publicly. The German regulatory apparatus, argues Jasanoff, seeks consensus by incorporating as broad a range of "interests and positions" (p262) as possible into its deliberative bodies. The subsequent work of the deliberative bodies themselves is insulated from the broader public, thereby shielding the public from witnessing expert disagreements which can undercut the power of these expert bodies. 
In a similar fashion, the logic of information polarization might be countered by carving out a new knowledge-producing "center" of researchers, journalists, and platforms with a clear demarcation between legitimate and illegitimate knowledge producers. One starting point for this demarcation could be that the center will exclude all knowledge producers who tolerate white nationalism, conspiracy theories, and hate speech (though the definitions would have to be worked out among those deemed legitimate). This new center would not be an information ecosystem that privileges a view-from-nowhere or view-from-all-sides type of knowledge production. Instead, the members of this center would make its political commitments clear but ground themselves within a shared set of norms, drawn from journalism and research. The center's main goal would not be to produce "information" and "news" but to establish a public sphere of debate.

The center would face two key problems. First, who, exactly, would get to be a part of this center and what would be the shared norms the center would be grounded in? Second, what should the relationship be between the new center and those outside it? In answering these questions, the center would have to grapple with the logic of political polarization as well as the implications of living in a networked world.

On the first question, given political polarization, it should be clear that the new center should include more than just mainstream media institutions. It would mean, for instance, including conservative think tanks, National Review, and even The Daily Mail as part of the new center, along with platforms like Google, Facebook, Twitter, and YouTube, but excluding Breitbart, Infowars, and Gab. This demarcation would be based on two aspects: how much these institutions police white nationalism, conspiracy theories, and hate speech, as well as how grounded they are in the twin crafts of journalism and research. The expansion of the center would not be without its trade-offs: it might mean even more acrimonious debate over climate change policy as well as more power for established actors like corporations and lobbyists who have the resources to participate in this public sphere while adhering to its norms. But it might also make for a more inclusive public sphere, given the realities of polarization.

The second question-policing the boundaries of this new center-is far more challenging. As Whitney Phillips, the ethnographer of 4Chan and other troll-like communities has put it in a recent report (2018), "The choices reporters and editors make about what to cover and how to cover it play a key part in regulating the amount of oxygen supplied to the falsehoods, antagonisms, and manipulations that threaten to overrun the contemporary media ecosystem-and, simultaneously, threaten to undermine democratic discourse more broadly" (p2). It would be immensely tricky for the new center to both deprive the fringes of oxygen and also be more representative of the American political spectrum. Many problems could arise. For instance, given that digital journalism is built on advertising and engagement metrics, what would stop someone at the center from reporting on what's happening outside it? What happens when politicians themselves actively engage with the fringe (as when President Trump retweets conspiracy theories)? There is, however, some evidence that "regulating the amount of oxygen" can deprive the fringe of its audience. As Facebook, YouTube and Twitter have actively banned 
Alex Jones' Infowars portal from distributing articles on their platforms, Inforwars' viewership has been cut in half (Nicas 2018).

Of course, existing models of objectivity (the focus on facts, keeping facts and values separate) have an enormous stickiness. Thus, even in this polarized age, as political activists cast aspersions on particular media institutions, they remain somehow committed to the ideal of a value-free media, just as opponents of corporate-driven science still imagine science as value-free. As Sheila Jasanoff (2007) remarks poignantly in Designs on Nature:

The Mertonian vision of disinterested science is kept alive even by corporate science's most ardent American critics; not for them the [...] dream of a thoroughly socialized, politically embedded science. Moments of slippage do occur, as happened in biotechnology patent disputes and in recurrent controversies about the ethical status of university-industry relations. But in all these debates, it is a particular faulty development, corporation, or person that draws negative attention; the ideal of valuefree science retains its firm hold on the national imagination, of cheerleaders as well as skeptics. (p288)

To sum up, this essay argues that STS scholars-building on their sophisticated analyses of objectivity and trustworthiness-should turn their attention to how political polarization and technological change have led to the rise of alternative media ecosystems, with their own norms of objectivity. In studying post-truth, I propose we draw on the key insight from STS studies of objectivity: that these disagreements over facts are often just symptoms of a wider disagreement over values, and that these disagreements are materially, institutionally, and historically structured. The future of media objectivity in an age of polarization, Trump, and social media platforms might lie in understanding how various actors-academic researchers included-craft new civic epistemologies. That might be an area where STS scholars might make a useful contribution.

\section{Author Biography}

Shreeharsh Kelkar is a lecturer in the Interdisciplinary Studies Field Major at UC Berkeley. He studies how the emerging computing infrastructures of humans, algorithms, and data are transforming work and expertise.

\section{Acknowledgements}

I thank the one anonymous reviewer as well as the journal editors, Katie Vann and Daniel Lee Kleinman, for their incisive and generous feedback, all of which have greatly improved this article. Portions of this argument were published as blog-posts on Platypus, the blog of the Committee for the Anthropology of Science, Technology, and Computing (CASTAC), and for the Science, Knowledge, and Technology (SKAT) section of the American Sociological Association (ASA). 


\section{References:}

Achenbach, Joel. 2015. "Why Science Is so Hard to Believe." Washington Post, February 12. Accessed 1 April 2019. https: / / www.washingtonpost.com/opinions/ why-science-is-sohard-to-believe/2015/02/12/2ff8f064-b0a0-11e4-886b-c22184f27c35_story.html.

Ananny, Mike. 2018. Networked Press Freedom: Creating Infrastructures for a Public Right to Hear. Cambridge, MA: The MIT Press.

Anderson, C. W. 2018. Apostles of Certainty: Data Journalism and the Politics of Doubt. New York, NY: Oxford University Press.

Beck, Julie. 2017. “This Article Won't Change Your Mind." The Atlantic, March 13. Accessed 1 April 2019. https://www.theatlantic.com/science/archive/2017/03/this-article-wontchange-your-mind /519093/.

Berry, Jeffrey M., and Sarah Sobieraj. 2014. The Outrage Industry: Political Opinion Media and the New Incivility. 1st edition. Oxford; New York: Oxford University Press.

boyd, danah. 2018. "You Think You Want Media Literacy... Do You?" Data \& Society: Points, March 9. Accessed 1 April 2019. https://points.datasociety.net/you-think-you-wantmedia-literacy-do-you-7cad6af18ec2.

Collins, Harry, Robert Evans, and Martin Weinel. 2017. "STS as Science or Politics?" Social Studies of Science 47 (4): 580-86. DOI: https: / / doi.org/10.1177/ 0306312717710131.

Corley, Pamela C., Amy Steigerwalt, and Artemus Ward. 2013. The Puzzle of Unanimity: Consensus on the United States Supreme Court. 1st edition. Stanford, California: Stanford Law Books.

Daston, Lorraine, and Peter Galison. 2010. Objectivity. New York: Zone Books.

Davis, Jenny L., and Nathan Jurgenson. 2014. "Context Collapse: Theorizing Context Collusions and Collisions." Information, Communication \& Society 17 (4): 476-485. DOI: https:// doi.org/10.1080/1369118X.2014.888458.

Drum, Kevin. 2017. “Donald Trump Edits a Tweet." Mother Jones (blog), February 17. Accessed 1 April 2019. https://www.motherjones.com/kevin-drum/2017/02/donald-trump-editstweet/.

Farrell, Henry, and Daniel W. Drezner. 2007. "The Power and Politics of Blogs." Public Choice 134 (1): 15. DOI: https:// doi.org/10.1007/s11127-007-9198-1.

Flynn, D. J., Brendan Nyhan, and Jason Reifler. 2017. “The Nature and Origins of Misperceptions: Understanding False and Unsupported Beliefs about Politics." Political Psychology 38: 127-150. DOI: https:// doi.org/10.1111/pops.12394.

Frickel, Scott, Rebekah Torcasso, and Annika Anderson. 2015. "The Organization of Expert Activism: Shadow Mobilization in Two Social Movements." Mobilization: An International Quarterly 20 (3): 305-323. DOI: https:/ / doi.org/10.17813/1086-671X-20-3-305.

Fuller, Steve. 2016. "Embrace the Inner Fox: Post-Truth as the STS Symmetry Principle Universalized." Social Epistemology Review and Reply Collective (blog), December 25. Accessed 1 April 2019. https://social-epistemology.com/2016/12/25/embrace-theinner-fox-post-truth-as-the-sts-symmetry-principle-universalized-steve-fuller $/$. 
Gauchat, Gordon. 2012. "Politicization of Science in the Public Sphere: A Study of Public Trust in the United States, 1974 to 2010." American Sociological Review 77 (2): 167-87. DOI: https: / / doi.org/10.1177/0003122412438225.

Gillespie, Tarleton. 2010. “The Politics of 'Platforms.'” New Media \& Society 12 (3): 347-64. DOI: https: / / doi.org/10.1177/1461444809342738.

—— 2014. "The Relevance of Algorithms." In Media Technologies: Essays on Communication, Materiality, and Society, edited by Tarleton Gillespie, Pablo J. Boczkowski, and Kirsten A. Foot. Cambridge, MA: MIT Press.

—_. 2016. "Algorithms, Clickworkers, and the Befuddled Fury around Facebook Trends." Nieman Lab (blog), May 19. Accessed 1 April 2019. http:/ / www.niemanlab.org/2016/05/algorithms-clickworkers-and-the-befuddled-furyaround-facebook-trends/.

Graves, Lucas. 2016. Deciding What's True: The Rise of Political Fact-Checking in American Journalism. New York: Columbia University Press.

Grossmann, Matt, and David Hopkins. 2016a. "How the Conservative Movement Has Undermined Trust in Academe." Inside Higher Ed (blog), October 11. Accessed 1 April 2019. https://www.insidehighered.com/views/2016/10/11/how-conservativemovement-has-undermined-trust-academe-essay.

Grossmann, Matt, and David A. Hopkins. 2016b. Asymmetric Politics: Ideological Republicans and Group Interest Democrats. New York: Oxford University Press.

Helmreich, Stefan, and Heather Paxson. 2005. "Sex on the Brain: A Natural History of Rape and the Dubious Doctrines of Evolutionary Psychology." In Why America's Top Pundits Are Wrong: Anthropologists Talk Back, edited by Catherine Besteman and Hugh Gusterson, 180-205. Berkeley: University of California Press.

Hoffman, Steve G. 2018. "The Responsibilities and Obligations of STS in a Moment of Post-Truth Demagoguery." Engaging Science, Technology, and Society 4: 444-452. DOI: https:// doi.org/10.17351/ests2018.259.

Jasanoff, Sheila. 2007. Designs on Nature: Science and Democracy in Europe and the United States. Princeton, NJ: Princeton University Press.

Kahan, Dan M., David A. Hoffman, Danieli Evans, Neal Devins, Eugene Lucci, and Katherine Cheng. 2015. “'Ideology' or 'Situation Sense'? An Experimental Investigation of Motivated Reasoning and Professional Judgment." SSRN Scholarly Paper ID 2590054. Rochester, NY: Social Science Research Network. https: / / papers.ssrn.com/abstract=2590054.

Katznelson, Ira. 2005. When Affirmative Action Was White: An Untold History of Racial Inequality in Twentieth-Century America. 1st edition. New York: W. W. Norton \& Co. Inc.

Kolbert, Elizabeth. 2017. “Why Facts Don't Change Our Minds.” The New Yorker, February 20. Accessed 1 April 2019. https:/ / www.newyorker.com/magazine/2017/02/27/ why-factsdont-change-our-minds.

Konnikova, Maria. 2014. "I Don't Want to Be Right." The New Yorker, May 16. Accessed 1 April 2019. https: / / www.newyorker.com/ science/ maria-konnikova/i-dont-want-to-be-right. 
Losse, Kate. 2019. "The False Promise of Silicon Valley's Quest to Save the World." The New $\begin{array}{llllll}\text { Republic, } & \text { February } & 7 . & \text { Accessed } & 1 & \text { April }\end{array}$ https: / / newrepublic.com/article/153034/ false-promise-silicon-valleys-quest-saveworld.

Marres, Noortje. 2018. "Why We Can't Have Our Facts Back." Engaging Science, Technology, and Society 4: 423-443. DOI: https:/ / doi.org/10.17351/ests2018.188.

Marwick, Alice E., and danah boyd. 2011. "I Tweet Honestly, I Tweet Passionately: Twitter Users, Context Collapse, and the Imagined Audience." New Media \& Society 13 (1): 114-133. DOI: https:/ / doi.org/10.1177/1461444810365313.

Mooney, Chris. 2011. “The Science of Why We Don't Believe Science." Mother Jones, May. Accessed 1 April 2019. https:/ / www.motherjones.com/politics/2011/04/ denial-sciencechris-mooney/.

- 2012. The Republican Brain: The Science of Why They Deny Science- and Reality. 1st edition. Hoboken, N.J. : Chichester: Wiley.

— . 2015. "The Science of Why You Really Should Listen to Science and Experts." Washington Post, April 6. Accessed 1 April 2019. https:// www.washingtonpost.com/news/energyenvironment/wp/2015/04/06/the-science-of-why-you-really-should-listen-to-experts/

Nicas, Jack. 2018. “Alex Jones Said Bans Would Strengthen Him. He Was Wrong.” The New York Times, November 26. Accessed 12019. https:// www.nytimes.com/2018/09/04/technology/alex-jones-infowars-banstraffic.html.

Nissenbaum, Helen. 2009. Privacy in Context: Technology, Policy, and the Integrity of Social Life. 1st edition. Stanford, Calif: Stanford Law Books.

Nunez, Michael. 2016. "Former Facebook Workers: We Routinely Suppressed Conservative News." Gizmodo, May 9. Accessed 1 April 2019. https:/ / gizmodo.com/former-facebookworkers-we-routinely-suppressed-conser-1775461006.

Phillips, Whitney. 2018. "The Oxygen of Amplification: Better Practices for Reporting on Extremists, Antagonists, and Manipulators Online." Data and Society: Reports. Accessed 1 April 2019. https:/ / datasociety.net/output/oxygen-of-amplification/.

Porter, Theodore M. 1996. Trust in Numbers: The Pursuit of Objectivity in Science and Public Life. Princeton, NJ: Princeton University Press.

Resnick, Brian. 2017. "7 Psychological Concepts That Explain the Trump Era of Politics." Vox. March 20. Accessed 1 April 2019. https://www.vox.com/science-andhealth/2017/3/20/14915076/7-psychological-concepts-explain-trump-politics.

Sarewitz, Daniel. 2004. “How Science Makes Environmental Controversies Worse." Environmental Science \& Policy 7 (5): 385-403. DOI: https: / / doi.org/10.1016/j.envsci.2004.06.001.

Schudson, Michael. 1981. Discovering The News: A Social History Of American Newspapers. 2nd edition. New York, NY: Basic Books.

Shapin, Steven. 1995. A Social History of Truth: Civility and Science in Seventeenth-Century England. 1st ed. Chicago: University of Chicago Press. 
Sides, John, and Daniel J. Hopkins, eds. 2015. Political Polarization in American Politics. New York: Bloomsbury Academic.

Sismondo, Sergio. 2017. "Post-Truth?" Social Studies of Science 47 (1): 3-6. DOI: https: / / doi.org/10.1177/0306312717692076.

Starr, Paul. 2005. The Creation of the Media: Political Origins of Modern Communications. 1st edition. New York, NY: Basic Books.

Thompson, Nicholas, and Fred Vogelstein. 2018. "Inside Facebook's Two Years of Hell." Wired, February 12. Accessed 1 April 2019. https://www.wired.com/story/inside-facebookmark-zuckerberg-2-years-of-hell/.

Tucker, Joshua A., Andrew Guess, Pablo Barbera, Cristian Vaccari, Alexandra Siegel, Sergey Sanovich, Denis Stukal, and Brendan Nyhan. 2018. "Social Media, Political Polarization, and Political Disinformation: A Review of the Scientific Literature." SSRN Scholarly Paper 3144139. Rochester, NY: Social Science Research Network. https: / / papers.ssrn.com/ abstract=3144139. 